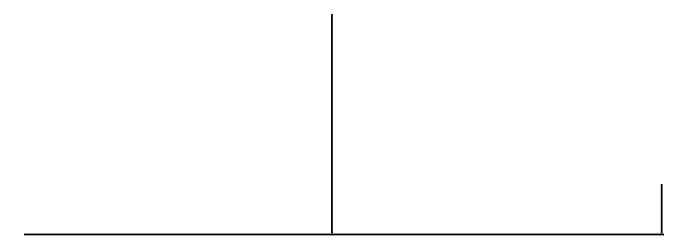

Rev. Latinoam. Psicopat. Fund., São Paulo, v. 15, n. 2, p. 419-434, junho 2012

\title{
Afinal, quem foi Sacher-Masoch?
}

\author{
Cassandra Pereira França \\ Júlia de Sena Machado
}

$O$ artigo pretende aprofundar o conhecimento a respeito do masoquismo, resgatando dados da biografia e da obra de Sacher-Masoch, com base na leitura de Gilles Deleuze. Lendo A Vênus das peles, constata-se que Sacher-Masoch explicita os aspectos formal, estético e contratual do masoquismo, propostos por Deleuze. Justifica-se a importância de se ler diretamente a obra de Masoch para se ter acesso a aspectos da lógica do masoquismo que não têm sido levados em conta nos estudos sobre o tema.

Palavras-chave: Masoquismo, Sacher-Masoch, psicanálise, literatura 


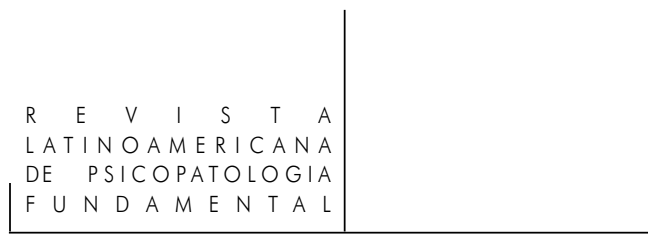

A entidade "masoquismo" porta, aparentemente, o tom de uma homenagem conferida a Sacher-Masoch, uma vez que o conceito inspirado no nome desse escritor popularizou-se e entrou definitivamente não apenas no vocabulário médico e psicanalítico, mas também no vocabulário leigo. No entanto, à medida que o termo foi sendo difundido, a obra de Sacher-Masoch foi, simultaneamente, sendo deixada de lado, levando leitores e críticos desse escritor austríaco a ficarem sensibilizados e a acusarem o sexólogo Krafft-Ebing - criador do conceito - de ter reduzido o nome de um grande escritor ao de uma doença. O próprio Sacher-Masoch reagiu ao fato, protestando "contra aquela apropriação de seu nome, recusando o destino de vir a figurar na história como 'perverso' ou 'pervertido', ou mesmo como libertino". 'Segundo o historiador francês Bernard Michel (1992), ele teria recusado com indignação tal situação, afinal:

Vivera um destino de criador, fora o amante inventivo de esplêndidas amantes; não podia admitir que tudo isso fosse rebaixado ao nível de uma doença sexual. Tanto quanto El Greco não podia aceitar que sua pintura fosse apenas o resultado de perturbações visuais, ou Van Gogh que o mundo por ele criado não refletisse mais do que uma simples desordem mental. (p. 7)

Krafft-Ebing (1999), por sua vez, apesar de reconhecer o talento de Sacher-Masoch como escritor, refutou as acusações de que teria reduzido o nome de um autor de renome àquele de uma perversão do instinto sexual, tecendo comentários que acirraram ainda mais a polêmica:

Sinto-me justificado em chamar essa anomalia sexual de masoquismo, porque o autor Sacher-Masoch frequentemente fez dessa perversão, que, até então, era consideravelmente desconhecida pelo mundo científico como tal, o substrato de seus escritos. [...] Nos anos recentes, houve avanço nos fatos que provam que Sacher-Masoch foi não apenas o poeta do masoquismo, mas que ele próprio era afligido pela anomalia. (p. 120, tradução nossa)

1. Flávio Carvalho Ferraz, na Introdução de A Vênus das peles (Sacher-Masoch, 2008, p. 11). 


\section{MOVIMENTOS}

LITERÁRIOS

Mas, afinal, quem foi Leopold von Sacher-Masoch? Dizer que foi o escritor cujo nome inspirou a criação do termo masoquismo é muito pouco, pois, mais que isso, ele foi o autor de uma obra diversificada que, captando as forças do romantismo alemão, enlaçava a condição humana ao erotismo, pautando a escrita dessa condição em questões de cunho histórico, cultural, místico e político destacando problemas relativos às minorias, aos nacionalismos e aos movimentos revolucionários do antigo Império Austro-Húngaro. Como aponta Ferraz (2008), tendo em vista a riqueza de elementos psicológicos e artísticos presentes na obra de Sacher-Masoch, ela pode ser adotada como referência em distintos campos do saber.

Dentre os poucos teóricos que se dedicaram ao estudo do conjunto dos escritos e da biografia de Sacher-Masoch, destacam-se o historiador Bernard Michel e o filósofo Gilles Deleuze, que, em suas análises, valeram-se das informações sobre a vida do escritor deixadas por seu secretário, Schilichtegroll, autor de Sacher-Masoch und der Masochismus ${ }^{2}$ [Sacher-Masoch e o masoquismo] e por sua primeira esposa Wanda von Sacher-Masoch, autora de Meine Lebensbeichte ${ }^{3}$ [Confissão da minha vida].

Sacher-Masoch viveu 59 anos, entre 1836 e 1895. Nasceu em Lemberg, cidade situada na região da Galícia - província ao sul da Polônia que em 1772 havia sido incorporada ao Império Austro-Húngaro (atual Lvov, na Ucrânia). Membro da aristocracia austríaca, ainda pequeno aprendeu o francês, língua em que foi alfabetizado, juntamente com o alemão, para estudar ciência e filosofia. Apesar de ser um homem de fronteira, pois nasceu entre o mundo russo e o germânico, escrevia em língua alemã, "na qual pensava e sentia". ${ }^{4}$

A entrada do nome de Sacher-Masoch no meio médico e, especificamente, nas discussões a respeito das perversões deve-se à relação estabelecida entre seus escritos e os relatos a respeito de suas experiências amorosas, as quais, segundo o próprio autor, desaguavam em seu processo criativo:

[...] todos os meus romances, quando não tratam de um assunto histórico, nasceram de minha vida, banharam-se no sangue do meu coração. Que me compreendam bem, não fiz romances, a partir dos diversos capítulos de minha biografia, isto estaria bem longe da arte, mas em cada uma de minhas narrativas há um nervo que é meu, há motivos que são extraídos de minha vida. Mesmo quando a fábula é inteiramente inventada, não é o caso dos caracteres, não é o caso das cenas e dos detalhes. Na minha obra a pintura é sempre propriedade do poeta,

2. Publicado em 1901, disponível apenas em alemão.

3. Datado de 1990 e originalmente publicado em 1907.

4. Flávio Carvalho Ferraz, na Introdução de A Vênus das peles (Sacher-Masoch, 2008). 
mas a tela em que nasceu assim como sua impressão pertencem à minha pessoa, à minha vida. ${ }^{5}$ (Sacher-Masoch, 1895, citado por Michel, 1992, p. 8)

Algumas das amantes ${ }^{6}$ de Sacher-Masoch foram a público confirmar que vida e obra dele eram entrelaçadas pela escrita. Exemplo disso seria a mais célebre obra do escritor, A Vênus das peles (Venus im Pelz, 1870), que teria sido baseada no relacionamento amoroso vivido por Sacher-Masoch e Fanny von Pistor. As memórias que o amante preservara desse relacionamento resultaram, na obra, em um romance dentro do romance, estabelecendo uma relação de mise en abyme $e^{7}$ entre o vivido e o escrito por Sacher-Masoch. O leitor está dentro e fora da obra - somos colocados diante do abismo (abyme) -, e a obra dentro da obra gera um efeito de espelhamento que produz uma confusão entre ficção e realidade. Pouco a pouco, damo-nos conta de que se trata das memórias relativas ao relacionamento amoroso de Severin von Kusiemski e Wanda von Dunajew (personagens da ficção). Severin é um sonhador idealista e solitário, que vive em busca da mulher ideal: a encarnação da deusa Vênus, uma mulher-deusa, déspota, gélida, sensual e "ultracruel". Wanda é uma bela e jovem viúva, que se apaixona pelo olhar idealizador de Severin, mas que, ao contrário dele, defende um amor sem culpa, indolor e que seja oficializado por meio do casamento.

Para Severin, o relacionamento do casal deveria, necessariamente, envolver uma assimetria de forças e de poder, havendo duas posições distintas a serem ocupadas: a do martelo e a da bigorna, ou, dito de outro modo, a do senhor e a do escravo. Essa nos parece ser a questão fundamental para a qual aponta o romance vivido e escrito por Sacher-Masoch, a saber: ele só pode gozar se a relação sexual envolver uma assimetria de poderes entre o homem e a mulher, sendo que ele deve ocupar a posição de escravo, enquanto ela deve assumir a posição de sua senhora. Desse modo, a dinâmica do romance é ditada por ele, ainda que ocupe a posição de um humilde escravo da mulher.

No caso de Severin, a satisfação sexual é condicionada aos maus-tratos sofridos e, por isso, ele exige que Wanda o trate cruelmente. Tal exigência gera, nela,

5. Citação extraída por Michel (1992) de Eine Autobiographie (1979) em: Souvenirs autobiographische Prosa. Belleville: [s.n.], 1985, p. 74.

6. Destacando-se, dentre elas, Wanda von Sacher-Masoch (pseudônimo de Aurore Rümelin) esposa de Sacher-Masoch entre 1873 e 1886 e autora de Meine Lebensbeichte [Confissão da minha vida], livro publicado em Berlim em 1906.

7. Remete-se, aqui, a uma técnica de pintura que reproduz - em um efeito de espelhamento -, repetidamente, algum detalhe do quadro. A composição em abismo, possibilitada por tal técnica, dilui, portanto, as fronteiras entre a representação e a representação da representação, o que coloca em questão o limite entre o elemento real e a representação deste. 
MOVIMENTOS

LITERÁRIOS

estranhamento, afinal, ela quer "apenas" um casamento "normal". Por isso, Severin tem que despender grandes esforços a fim de convencê-la a ocupar "o lugar do martelo", permitindo, assim, a realização da fantasia sexual dele. A sedução é realizada por intermédio do poder de persuasão do masoquista, o qual "deve ser talentoso o suficiente para convencer seu parceiro a causar-lhe sofrimento". ${ }^{8}$ A arma utilizada por Severin para tal convencimento é o idealismo: seduz a parceira, alimentando nela a esperança de vir a ocupar o lugar do ideal dele. Para encarnar aquela mulher opulenta e má, que domina o imaginário dele, ela é instruída, detalhadamente, sobre cada gesto que deve esboçar (o que deve falar; o que deve vestir; como e quando deve maltratá-lo).

$\mathrm{Na}$ fantasia sexual de Severin, a maneira como a mulher age é ritualística: ela veste peles sempre que quer ser cruel para com seu escravo; empunha um látego e fustiga-o com um sorriso cruel; trata-o como um objeto; pratica adultério, fazendo-o sentir-se rejeitado e humilhado. Só assim ela consegue proporcionar ao parceiro a satisfação (sempre parcial) do desejo dele, sendo que esse desejo aponta para uma angústia mortal.

\section{Controle e descontrole no masoquismo}

A Vênus das peles ilustra de forma única o desejo do sujeito masoquista de ser colocado na posição passiva e de ser punido, tal como a criança desobediente e má do texto freudiano "Uma criança é espancada" (1919), no qual Freud descreve três modelos de masoquismo: o erógeno, o masoquismo feminino e o masoquismo moral. Todos esses tipos encontram-se belamente ilustrados pelo personagem do romance que ora comentamos. Vejamos. Nota-se, no caso de Severin, a presença do masoquismo erógeno tornado efetivo pelos golpes de chicote, exposição ao frio, à fome, à privação de sono e dinheiro, além de péssimas condições de sobrevivência. Já o masoquismo feminino se presentifica pela exigência que ele faz de ser apassivado durante a relação sexual, isto é, de que a mulher manipule seu corpo (aparentemente) a despeito da vontade dele. Finalmente, o masoquismo moral pode ser visto como fruto do constrangimento provocado pelo adultério cometido, a seu pedido, pela companheira. Severin dizia "mortificar-se" diante da ideia de que sua amada o trocasse por outro homem e, justamente por isso (indo na direção da morte), chegou a ponto de exigir que ela elegesse um amante que o amarrasse e surrasse - evidência da necessidade do

8. Flávio Carvalho Ferraz, na Introdução de A Vênus das peles (Sacher-Masoch, 2008, p. 15). 
masoquista de controlar até aquilo que, dizendo respeito ao desejo do outro, escapa ao seu controle. Por trás do "mortificante" temor de ser traído, havia o desejo não apenas de que o adultério se consumasse, mas também o de que ele próprio pudesse escolher o amante de sua mulher.

Vemos assim, ao longo de quase uma centena de páginas do livro A Vênus das peles, o quanto o escravo, na relação masoquista, dirige o estabelecimento da relação de submissão, incutindo na dinâmica da senhora e do escravo a ameaça de que a realização do desejo do masoquista faça com que ele perca o controle da relação, sendo então conduzido, pelas mãos de sua ama, ao encontro da morte. A angústia de morte é o fantasma que ronda o romance e que ilustra um dos maiores méritos de Sacher-Masoch: o de ter abordado, de modo corajoso, um aspecto misterioso e intrigante da alma humana, que seria mais tarde descrito por Freud, a saber, a busca por um tipo de prazer que só pode ser sentido como desprazer.

\section{O batismo do masoquismo}

Mas, um ano antes que $A$ Vênus das peles viesse a público, foi lançado o manual Psychopathia sexualis (1869), escrito pelo psiquiatra, neurologista e sexólogo austríaco Richard von Krafft-Ebing, professor da Universidade de Viena e contemporâneo de Freud, que identificava, na obra de Sacher-Masoch, a presença de um relato de uma perversão sexual que não havia, até então, sido descrita: o masoquismo. Valendo-se do nome de Masoch, o sexólogo assim a catalogava:

Por masoquismo eu entendo uma perversão peculiar da vida sexual psíquica, na qual o indivíduo afetado, em sentimento e pensamento sexual, é controlado pela ideia de estar completa e incondicionalmente sujeito à vontade de uma pessoa do sexo oposto; de ser tratado por essa pessoa como por um mestre, humilhado e abusado. Essa ideia é colorida por um sentimento cheio de sensualidade; o masoquista vive em fantasias, nas quais ele cria situações desse tipo e frequentemente tenta realizá-las. (Krafft-Ebing, 1999, p. 119, grifo nosso, tradução nossa)

Krafft-Ebing destaca, assim, algo que nos parece fundamental no estudo do masoquismo: o sujeito é controlado por ideias de submissão e, desse modo, não vive o masoquismo, mas é por ele vivido. ${ }^{9}$ No entanto, o sexólogo interpretava as manifestações do masoquismo de forma moralizante, associando-as à condu-

9. Aspecto que seria sublinhado por Freud em "O ego e o id" (1923).

Rev. Latinoam. Psicopat. Fund., São Paulo, v. 15, n. 2, p. 419-434, junho 2012 


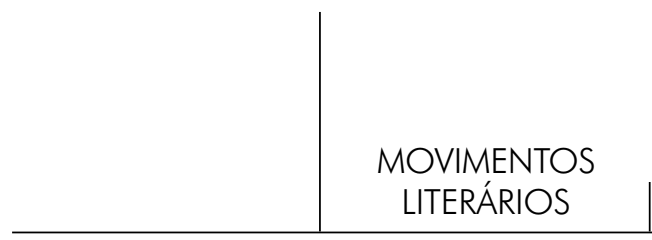

ta criminosa e exigindo um posicionamento repressor do Estado com relação a esses comportamentos. Ele atribuía a causa do masoquismo a uma degenerescência moral, a qual se desenvolveria a partir de uma degenerescência biológica. ${ }^{10}$

Ao dar nome ao masoquismo, Krafft-Ebing instituiu um quadro clínico original. Mas não parou por aí e classificou tal quadro como uma patologia e o colocou junto a tudo aquilo que, em seu catálogo do comportamento sexual humano, era considerado exemplo de "aberração" da sexualidade humana, abarcando uma vasta gama de comportamentos que iam do homossexualismo ao estupro, das práticas que envolviam mutilações à necrofilia, inclusive a pedofilia, o fetichismo, o voyeurismo, o exibicionismo etc. A despeito do sentido "patologizante" incutido no termo masoquismo, Krafft-Ebing contribuiu para os estudos sobre o tema ao ressaltar aspectos fundamentais do quadro clínico por ele descrito. Por exemplo, a função da imaginação e da fantasia como motores da satisfação masoquista; o idealismo presente nesse quadro e o desejo (de caráter incontrolável) de ser apassivado e submetido à escravidão e à humilhação.

\section{O impacto da/na obra de Sacher-Masoch}

A associação entre o nome de Sacher-Masoch e o masoquismo - então considerado uma patologia - foi determinante no que diz respeito ao destino da obra desse autor. Por um lado, é preciso reconhecer, tal associação contribuiu significativamente para a divulgação do nome de Sacher-Masoch nos meios literários e intelectuais de todo o mundo ocidental. Mas ele já era um escritor reconhecido e várias de suas obras já haviam sido traduzidas para outros idiomas. Um exemplo do reconhecimento que Sacher-Masoch teve como escritor é o fato de A Vênus das peles ter sido uma das referências usadas por Kafka (um dos maiores escritores da língua alemã do século XX) ao escrever A metamorfose em $1915 .{ }^{11}$

10. Esta ideia foi desenvolvida por Flávio Carvalho Ferraz na Introdução de $A$ Vênus das peles (Sacher-Masoch, 2008).

11. No início dessa célebre ficção, Kafka faz alusão à pintura Vênus no espelho, do renascentista veneziano Ticiano Vecellio (1490-1576), citada, anos antes, por Sacher-Masoch, nas primeiras páginas de $A$ Vênus das peles. Kafka também se apropriou de alguns nomes dos personagens do romance de Sacher-Masoch para dar nome ao seu personagem principal: Gregor Samsa. No romance de Sacher-Masoch, Gregor é um personagem que entra na trama para formar um triângulo amoroso com Severin e Wanda. 
No entanto, para alguns, a criação da entidade masoquismo, por si só, explica a impopularidade da obra de Sacher-Masoch, escritor cujo nome foi caindo no esquecimento, ao mesmo tempo que o uso da palavra "masoquismo" foi se tornando comum. Sensibilizado por essa questão, Deleuze (2009) faz a seus leitores o convincente apelo de resgatar Sacher-Masoch do esquecimento para que, com ele, possamos aprender sobre o masoquismo. Afinal, ao contrário do que ocorre com Sade, Sacher-Masoch é raramente citado nas discussões literárias e clínicas. Nesse sentido, seria preciso ler e analisar clinicamente a obra desse autor, assim como já se faz com a de Sade, para que a reflexão clínica sobre o masoquismo possa se beneficiar da reflexão literária sobre a obra de Sacher-Masoch e vice-versa.

Deleuze (2009) considera que a obra de Sacher-Masoch apresenta aspectos absolutamente originais, constituindo-se como uma referência singular e preciosa para os estudos sobre o masoquismo. Segundo o filósofo, a originalidade da produção literária de Sacher-Masoch reside, justamente, no fato de o autor escrever a partir de seu "sentimento de vida". Originalidade fortemente marcada pelo senso estético da obra, destacando-se, nesse ponto, o modo como o erotismo é abordado, assim como o viés jurídico que nela se desenvolve por meio de distintos contratos - denominados por Deleuze contratos de submissão -, tais como os que foram firmados entre os personagens de A Vênus das peles. Munido desses argumentos, e ancorado na literatura, Deleuze convida-nos a ler e analisar a obra de Sacher-Masoch, buscando aspectos do masoquismo que permanecem, ainda, fora das análises médicas, psicológicas e psicanalíticas sobre o tema. Aceitemos, então, esse instigante convite.

\section{$O$ resgate da obra pela via da literatura}

A obra de Sacher-Masoch é utilizada por Deleuze como uma espécie de cartografia, um mapa com coordenadas que orientam o filósofo em seu pensamento crítico sobre o masoquismo, permitindo a ele lançar algumas questões relevantes, entre as quais se encontram as seguintes: $\mathrm{O}$ masoquismo se resumiria a uma patologia clínica? O masoquismo seria o oposto complementar do sadismo? A concepção freudiana do sadomasoquismo está de acordo com a descrição que Sacher-Masoch faz do masoquismo? Sigamos essas coordenadas.

Deleuze ressalta que é importante ter a cautela de não concluir rapidamente que o masoquismo é uma doença ou, ainda, uma aberração. Segundo o filósofo, a escrita de Sacher-Masoch leva-nos a experimentar o sentimento de vida do 


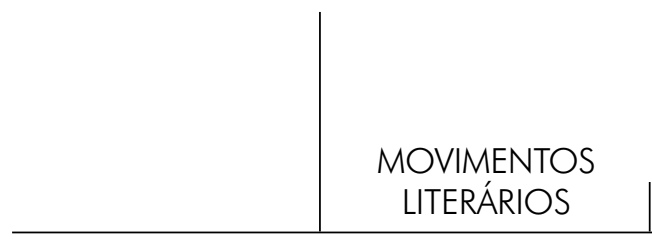

poeta do masoquismo, ${ }^{12}$ permitindo pensar sobre esse fenômeno clínico com base em uma experiência estética, dando-nos acesso a detalhes da experiência masoquista que não teriam sido abordados por Freud, apesar dos grandes passos dados por esse autor na análise do masoquismo. Enquanto Deleuze aborda o sentimento de vida, Ferraz ${ }^{13}$ fala do modo de vida ao analisar A Vênus das peles. Nessa perspectiva, o modo de vida seria uma forma particular que o sujeito inventa de estar no mundo e de experimentar a sexualidade, o que se traduziria em uma

[...] experiência, não apenas sensorial, mas sobretudo estética, que se manifesta em um livro como A Vênus das peles [e que] faz dessa literatura uma produção sofisticada que traz à luz os mistérios mais profundos da alma e da sexualidade humana que, se se fazem presentes na superfície [do comportamento] do masoquista, não deixam de existir nas profundezas inconscientes do dito "normal", ou seja, do humano universal. Sadismo e masoquismo, como se depreende da obra destes autores, não se resumem a meros sintomas ou doenças - perversões, de acordo com a psicanálise, ou parafilias, de acordo com o linguajar psiquiátrico contemporâneo - mas refletem amplamente modos de vida. ${ }^{14}$

Gilles Deleuze discorda radicalmente do paralelismo entre masoquismo e sadismo feito por Krafft-Ebing a partir das obras de Sacher-Masoch e do Marquês de Sade. Tal paralelismo parecia perfeito aos olhos do sexólogo, como podemos constatar na seguinte passagem: "sadismo e masoquismo [...] estão tão intimamente relacionados e correspondem tão bem em todos os pontos, que um permite, por analogia, a conclusão sobre o outro" (Krafft-Ebing, 1999, p. 183). Deleuze considera que tal concepção, além de não ser correta, foi prejudicial para a obra de Sacher-Masoch, já que esta deixou de ser lida e consultada nos estudos sobre o masoquismo, sendo substituída pela leitura dos textos do Marquês de Sade: "de forma apressada, achou-se que basta inverter os signos, subverter as pulsões e pensar na grande unidade dos contrários para se obter Masoch a partir de Sade" (Deleuze, 2009, p. 12-13).

De acordo com Deleuze, o enlaçamento entre masoquismo e sadismo operado por Krafft-Ebing teria levado à errônea interpretação de que estes seriam sentimentos de vida complementares - união que, aliás, acabou sendo consagrada, reafirmada e divulgada pela teoria freudiana ao se apropriar da entidade "sadomasoquista" proposta por Krafft-Ebing. Ao se opor a esse "casamento

12. Modo como Deleuze se refere, em alguns momentos, a Sacher-Masoch.

13. Vide Introdução de A Vênus das peles (Sacher-Masoch, 2008).

14. Flávio Carvalho Ferraz, na Introdução de A Vênus das peles (Sacher-Masoch, 2008, p. 17, grifos nossos).

Rev. Latinoam. Psicopat. Fund., São Paulo, v. 15, n. 2, p. 419-434, junho 2012 
conceitual", Deleuze explica-nos que o sadismo e o masoquismo, vistos pelo viés literário, resultam em duas estéticas distintas, caracterizadas por aspectos formais dissociados: o sadismo seria mais do que o desejo de causar sofrimento, e o masoquismo, mais do que o desejo de sofrer.

Essas e outras questões são discutidas por Deleuze em Sacher-Masoch: o frio e o cruel (2009), ao examinar cuidadosamente o modo como Sacher-Masoch discorre sobre os afetos e as experiências ligadas ao prazer derivados da dor e da humilhação. Nesse "resgate" da obra do poeta do masoquismo, o filósofo ressalta passagens do texto de Sacher-Masoch que permitiriam considerar o masoquismo uma linguagem e uma manifestação estética particulares, uma nova língua, uma forma de experimentar e descrever o mundo, e, ainda, uma linhagem clínica absolutamente irredutível ao sadismo. Desse modo, Deleuze reforça que o termo masoquismo - assim como o sadismo - diz respeito a um sentimento de vida, e não propriamente a uma patologia (como propusera Krafft-Ebing), ou a uma manifestação da pulsão de morte (tal qual propusera Freud em alguns momentos). Como exemplo da perspectiva freudiana a respeito do masoquismo, podemos rever a definição que esse autor confere ao masoquismo erógeno, em "O problema econômico do masoquismo" (1924). Nesse texto, Freud dá destaque ao masoquismo primário, que passou a ser chamado de masoquismo erógeno,

[...] um masoquismo que se aproxima da pulsão de morte. Podemos dizer que a pulsão de morte atuante no organismo - o sadismo original - seria idêntica ao masoquismo. Diríamos, então, que após a parcela principal do sadismo original ter sido transposta para fora em direção aos objetos, um resíduo interno teria permanecido, e seria este o masoquismo propriamente dito, isto é, o masoquismo erógeno. (p. 105, grifo nosso)

Na passagem acima, constata-se que Freud aproxima o masoquismo erógeno da pulsão de morte e descreve o primeiro como sendo um resíduo do sadismo original. Vemos, assim, que, em 1924, o masoquismo permanece sendo, na metapsicologia freudiana, um derivado do sadismo. Deleuze tem razão ao afirmar que, ao longo de toda a obra freudiana, o masoquismo é atrelado ao sadismo. Hoje, quase cem anos após Freud ter publicado o texto do qual extraímos o excerto supracitado, a relação entre masoquismo e sadismo permanece, de modo geral, sendo vista como uma relação de paralelismo e intercambialidade.

\section{Deleuze escolhe outro ângulo de análise}

Para Deleuze (2009), "nesse campo da psicanálise formal, ninguém foi tão longe quanto Theodor Reik no que diz respeito ao masoquismo" (p. 75). Por isso, 


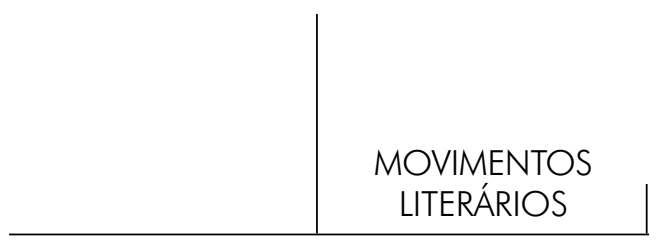

o filósofo baseia suas ideias sobre o tema nas de Reik, mais especificamente nas características fundamentais do masoquismo descritas por este último em Le masochisme (1941), sendo elas as seguintes:

1) a "significação especial da fantasia", quer dizer, a forma da fantasia (a fantasia vivida por si mesma ou a cena sonhada, dramatizada, ritualizada, absolutamente indispensável ao masoquismo); 2) o "fator suspensivo" (a espera, o atraso exprimindo a maneira pela qual a angústia age sobre a tensão sexual e a impede de crescer até o orgasmo); 3) o "traço demonstrativo", ou antes persuasivo (pelo qual o masoquista exibe o sofrimento, o embaraço e a humilhação); 4) o "fator provocador" (o masoquista agressivamente exige a punição como aquilo que resolve a angústia e lhe proporciona o prazer proibido). (Reik, 1941, citado por Deleuze, 2009, p. 76)

Recapitulemos brevemente essa análise que Reik faz dessas características do masoquismo. No primeiro ponto - "a significação especial da fantasia" para o masoquista -, Reik segue o mesmo caminho da construção fantasmática dos neuróticos apresentada por Freud em 1919 no texto "Uma criança é espancada" e que, por ser tão conhecida, dispensa nossos comentários. No entanto, ao descrever as outras três características do masoquismo, ele realiza uma leitura original do tema, baseando-se em minuciosa análise de uma coletânea de casos clínicos, acumulada ao longo de duas décadas de prática clínica. Vejamos.

A estética masoquista manifesta-se na montagem (não apenas em termos imaginários, mas também factuais) de uma cena, na qual ganha forma a fantasia masoquista. Essa cena seria marcada pelo "fator suspensivo" - presente pela sensação de expectativa provocada no leitor pelo discurso do personagem - ou seja, a suspensão (temporal) do gozo e sua postergação criam uma expectativa, não apenas no observador, mas também no próprio masoquista, de que algo está prestes a acontecer (Reik, 1941).

O "traço demonstrativo" (ou persuasivo) diz respeito ao modo como o masoquista exibe para o outro o seu sofrimento e a sua humilhação, tentando convencer o outro de que está entregue aos maus-tratos alheios. A análise do traço demonstrativo orientou as proposições de Deleuze a respeito da estética do masoquismo, uma vez que tal traço diz respeito às manobras operadas pelo sujeito masoquista para provocar no expectador (no leitor, no ouvinte, no observador) um engodo imaginário, que leva o outro a crer que ele (o sujeito masoquista) foi tornado vítima por outrem.

Já o "fator provocador" corresponde ao meio utilizado pelo masoquista para lidar não com o observador externo à cena, mas com seu parceiro sexual, a fim de extrair dele a punição de que necessita para, de acordo com Reik, driblar a angústia que o impede de gozar. $\mathrm{O}$ fator provocador seria o meio pelo qual o masoquista consegue provocar, pela ação do outro, a sua própria dor. Mas de que 
modo o masoquista convence seu parceiro a puni-lo? De que estratégias ele se vale para levar o parceiro a agir conforme seu (mortífero) desejo? Há limites para os maus-tratos? Haveria algum combinado, algum acordo?

Deleuze considera que haveria, no masoquismo, uma forma estrutural - que, no caso da perversão, seria bem enquadrada e ritualizada - de fazer operar essa provocação e garantir que castigos sejam empreendidos. A essa estrutura o autor dá o nome de função contratual da relação masoquista e considera curioso que Reik e outros analistas a tenham negligenciado (Deleuze, 2009). Dedicando-se à análise desse quinto fator, nosso comentarista irá recorrer aos contratos estabelecidos entre Severin e Wanda em A Vênus das peles. Pela escrita de tais contratos, Sacher-Masoch oferece ao seu leitor detalhes das fantasias de um masoquista e coloca em evidência as ações necessárias à concretização de tais fantasias. Afinal, elas só podem ser realizadas (ainda que parcialmente) por meio da participação de um outro que encarne o carrasco.

De acordo com Deleuze, no masoquismo a relação entre o servo e o carrasco é regulada pelo instituto emblemático de um contrato que, no caso da obra de Sacher-Masoch, assume a forma de um documento escrito que é assinado pelas partes envolvidas. Levando em conta, com Deleuze, que "o contrato de submissão" é fundamental na estruturação da relação masoquista e que a análise de tal contrato pode nos ajudar a entender o modo como o sujeito enlaça psiquicamente seu carrasco e como chega a concretizar suas fantasias sexuais, tomemos como ilustração do aspecto jurídico do masoquismo um dos mais interessantes contratos da obra A Vênus das peles. Trata-se de um documento redigido, na obra, por Wanda, a pedido de Severin, e firmado pelo casal, passando a funcionar como um regulador jurídico da relação. Segue o contrato:

\section{CONTRATO ENTRE A SENHORA WANDA VON DUNAJEW E O SENHOR SEVERIN VON KUSIEMSKY}

A contar da presente data, o senhor Severin von Kusiemsky passa a ser o noivo da senhora Wanda von Dunajew e renuncia a todos os seus direitos; ele, com sua palavra de honra na condição de homem e fidalgo, doravante fica obrigado a ser dela o escravo enquanto ela própria não lhe conceder a liberdade.

Na condição de escravo da senhora Von Dunajew, atenderá pelo nome de Gregor, satisfará a todos os seus desejos, obedecerá a todas as suas ordens, se mostrará sempre completamente submisso à sua dona, considerando todo e qualquer sinal de benevolência desta tão-somente um ato excepcional de piedade.

A senhora Von Dunajew deverá punir seu escravo a seu bel-prazer, não só pelo que lhe pareça o menor descaso ou a menor falta, como também terá o direito de o maltratar, seja por capricho, seja por passatempo, como bem lhe convier, matá-lo até mesmo, se assim o preferir; em suma terá sobre ele um direito de propriedade ilimitado.

Rev. Latinoam. Psicopat. Fund., São Paulo, v. 15, n. 2, p. 419-434, junho 2012 


\section{MOVIMENTOS}

LITERÁRIOS

Se a senhora Von Dunajew vier a conceder a liberdade a seu escravo, o senhor Severin von Kusiemsky se compromete a esquecer tudo o que experimentou ou suportou como escravo, e jamais, em tempo algum, sob nenhuma circunstância, cogitará vingança ou retaliação.

De sua parte, a senhora Von Dunajew compromete-se, na condição de dona de seu escravo, sempre que possível, a se apresentar com peles, especialmente quando tiver intenção de ser cruel para com ele.

Nestes termos encontram-se concordes na presente data. (Sacher-Masoch, 2008 , p. $105-106)^{15}$

A vítima (que também assina o contrato) não apenas está de acordo com as cláusulas que colocam em risco sua integridade física e moral, mas é justamente quem, a partir de seu desejo de submissão, propõe tais cláusulas. A elaboração desses contratos é, para Deleuze, o "mecanismo diferencial" do masoquismo e, por isso, o aspecto jurídico ganha destaque especial na leitura que o filósofo faz da obra de Sacher-Masoch. Ferraz considera que tais contratos explicitam que, na relação masoquista, o jogo erótico é, sobretudo, um jogo de poder. Nas palavras desse autor:

[...] a posição psíquica dos parceiros subverte qualquer lógica que se pretenda biológica ou mesmo social. Não se trata mais do papel sexual stricto senso ocupado na cena, mas sobretudo do lugar de poder que se ocupa na montagem [da cena erótica]. Para o ser humano não há mais sexo puramente biológico: seu regime passou a ser o psicológico. No domínio da fantasia e da linguagem, isto é, do que é peculiar ao humano, conta apenas o elemento simbólico, dado pelas significações inconscientes que se atribui ao outro. ${ }^{16}$

Analisando trechos das obras de Sacher-Masoch e de Deleuze, constatamos que uma relação pautada em uma lógica masoquista envolve um contrato de sub-

15. Esse contrato foi inspirado em um outro assinado entre Sacher-Masoch e Fanny Pistor. Aos 33 anos de idade, Sacher-Masoch conheceu Fanny, uma bela mulher, filha da aristocracia, a quem propôs o estabelecimento de um contrato semelhante ao que seria firmado, na literatura, entre Severin e Wanda, personagens de A Vênus das peles. O contrato estabelecido entre Sacher-Masoch e Fanny contém uma cláusula segundo a qual, em viagem à Itália, ela seduziria outro homem, que viria a ser seu amante, o qual deveria castigar Leopold a golpes de chicote. Em dados biográficos, consta que o amante de Fanny, um ator chamado Saviani, recusou-se a açoitar Sacher-Masoch. Mas, em A Vênus das peles - obra inspirada no romance vivido por Sacher-Masoch e Fanny -, o desfecho da história é corrigido: Severin é espancado pelo amante, a fim de tornar a ficção mais fiel à fantasia do autor. Podemos entender essa "correção" com base no que aponta Aristóteles em sua Poética: "não é ofício do poeta narrar o que aconteceu; é, sim, o de representar o que poderia acontecer, quer dizer: o que é possível segundo a verossimilhança e a necessidade" (Aristóteles, 1979, p. 249).

16. Flávio Carvalho Ferraz, na Introdução de A Vênus das peles (Sacher-Masoch, 2008, p. 16). 
missão (o qual pode ser instituído pelos parceiros por meio de um acordo explícito ou de um combinado implícito - sempre pela palavra) que regula a relação, garantindo o cumprimento das exigências daquele que, no nível manifesto, aparece como vítima. Ao ler Sacher-Masoch, fica evidente que o masoquista não cai, por azar, nas mãos de um(a) carrasco(a) cruel e perverso(a). A vítima buscou-o(a), encontrou-o(a), convenceu-o(a) a ocupar o lugar do(a) carrasco(a); trabalhou duramente em sua formação; adestrou-o(a) pedagogicamente para ser o(a) "dominador(a) todo-poderoso(a)"; instigou-o(a) e fomentou sua crueldade. Por isso, consideramos que, nesse tipo de relação, o masoquista deseja ocupar o lugar do objeto, e joga com a vida e com a morte, como podemos observar nas palavras contidas em um segundo documento apresentado em $A$ Vênus das peles: "Após anos de uma existência atribulada por fastios e decepções, por livre e espontânea vontade eu ponho fim à minha vida inútil” (Sacher-Masoch, 2008, p. 106). Nesse caso, o fim da vida não diz respeito à morte, mas à submissão a outrem.

Enfim, após todas essas leituras, mais uma vez constatamos que o encontro da psicanálise com a literatura - ambas dedicadas ao trabalho com a palavra - permite tecer, com os auspícios de poetas, prosadores e autores do campo da psicanálise, outra sorte de relação com o invisível e o indizível. Lendo Sacher-Masoch com Deleuze e Reik aprendemos sobre o masoquismo e temos mais um exemplo da razão pela qual Freud considerava a literatura um poderoso instrumento para se desvendar os mistérios da alma humana.

\section{Referências}

Aristóteles. Poética. São Paulo: Abril Cultural, 1979.

Deleuze, G. Sacher-Masoch: o frio e o cruel. São Paulo: Jorge Zahar, 2009.

FREUD, S. (1919). Uma criança é espancada: uma contribuição ao estudo da origem das perversões sexuais. In: StRachey, J. (ed.). The Standard Edition of the Complete Psychological Works of Sigmund Freud. Rio de Janeiro: Imago, 1969. v. 17, p. 223253.

. (1923). O ego e o id. In: Strachey, J. (ed.). The Standard Edition of the

Complete Psychological Works of Sigmund Freud. Rio de Janeiro: Imago, 1969. v. 19, p. 13-83.

(1924). O problema econômico do masoquismo. In: Hans, L. A. (coord.). Escritos sobre a psicologia do inconsciente. Tradução de E. V. K. P. Susemihl, H. Araújo, M. R. Salzano e L. A. Hanns. Rio de Janeiro: Imago, 2007. v. 3, p. 103-124.

Krafft-Ebing, R. von. (1886). Psychopathia sexualis. Burbank: Bloat, 1999. Tradução 
MOVIMENTOS

LITERÁRIOS

para o português da Twelfth English Edition of Psichopathia Sexualis, primeiramente publicada em 1903 por Ferdinand Enke, em Stuttgart.

Michel, B. Sacher-Masoch (1836-1895). Rio de Janeiro: Rocco, 1992.

ReIK, Th. Le masochisme. Paris: Payot, 1941. (Tradução francesa).

SACHER-Masoch, L. von. A Vênus das peles. Introdução de F. C. Ferraz. São Paulo: Erótica, 2008.

\section{Resumos}

(Well, who was Sacher-Masoch, anyway?)

This article goes into the topic of masochism, based on data from the biography and work of Sacher-Masoch, described in the writing of Gilles Deleuze. Readers of Deleuze's Venus in Furs will learn that Sacher-Masoch points out the formal, aesthetic and contractual aspects of masochism, proposed by Deleuze. We justify the importance of directly reading Sacher-Masoch to glean aspects of the logic of masochism that have not been taken into account in recent studies on the topic.

Key words: Masochism, Sacher-Masoch, psychoanalysis, literature

(Finalement, qui était Sacher-Masoch?)

Cet article cherche à approfondir les connaissances sur le masochisme tout en récupérant les données de la biographie et de l'œuvre de Sacher-Masoch, selon la lecture de Gilles Deleuze. À partir de la lecture de La Vénus à la fourrure, on peut constater que Masoch met en évidence les aspects formel, esthétique et contractuel du masochisme, proposés par Deleuze. Cet article justifie pourquoi il est primordial de lire directement l'œuvre de Masoch pour avoir accès aux aspects de la logique masochiste, étant donné que ceux-ci ne sont pas pris en compte lors des études sur ce sujet.

Mots clés: Masochisme, Sacher-Masoch, psychanalyse, littérature

(A final de cuentas, ¿quién fue Sacher-Masoch?)

El artículo pretende profundizar el conocimiento sobre el masoquismo, rescatando datos de la biografía y de la obra de Sacher-Masoch, basados en la lectura de Gilles Deleuze. Leyendo La Venus de las pieles, se constata que Sacher-Masoch explicita los aspectos formales, estéticos y contractuales del masoquismo, propuestos por Deleuze. Se justifica la importancia de leer directamente la obra de Masoch para tener acceso a aspectos de la lógica del masoquismo que no han sido considerados en los estudios sobre el tema.

Palavras claves: Masoquismo, Sacher-Masoch, psicoanálisis, literatura

Rev. Latinoam. Psicopat. Fund., São Paulo, v. 15, n. 2, p. 419-434, junho 2012 
(Wer war eigentlich Sacher-Masoch?)

Ziel dieses Beitrags ist die Vertiefung der Erkenntnisse bezüglich des Masochismus. Es sollen Angaben der Biographie und des Werkes von Sacher-Masoch aufgrund der Lektüre von Gilles Deleuze wiederaufgenommen werden. Bei der Lektüre von „Venus im Pelz“, ist festzustellen, dass Sacher-Masoch die von Deleuze vorgeschlagenen formalen, ästhetischen und ,vertraglichen“ Aspekte des Masochismus expliziert. Der Hinweis, unbedingt das Werk von Masoch selbst zu lesen ist insofern berechtigt, als dass man damit direkten Zugang zu den logischen Aspekten des Masochismus erlangt, die nicht in den Studien zum Thema beachtet wurden.

Schlüsselwörter: Masochismus, Sacher-Masoch, Psychoanalyse, Literatur

Citação/Citation: FrançA, C.P.; Machado, J.S. Afinal, quem foi Sacher-Masoch?. Revista Latinoamericana de Psicopatologia Fundamental, São Paulo, v. 15, n. 2, p. 419-434, jun.2012.

Editor do artigo/Editor: Fabiano Massarro Salvador

Recebido/Received: 1.3.2012 / 3.1.2012 Aceito/Accepted: 15.4.2012 / 4.15.2012

Copyright: () 2009 Associação Universitária de Pesquisa em Psicopatologia Fundamental/ University Association for Research in Fundamental Psychopathology. Este é um artigo de livre acesso, que permite uso irrestrito, distribuição e reprodução em qualquer meio, desde que o autor e a fonte sejam citados / This is an open-access article, which permits unrestricted use, distribution, and reproduction in any medium, provided the original author and source are credited.

Financiamento/Funding: As autoras declaram não ter sido financiadas ou apoiadas/The authors have no support or funding to report.

Conflito de interesses/Conflict of interest: As autoras declaram que não há conflito de interesses/The authors declares that has no conflict of interest.

\section{Cassandra Pereira França}

Doutora em Psicologia pela Pontifícia Universidade Católica de São Paulo - PUC-SP (São Paylo, SP, Br); Pós-doutorado em Psicologia pela mesma universidade; Professora Associada do Departamento de Psicologia da Universidade Federal de Minas Gerais - UFMG (Belo Horizonte, MG. Br); Psicóloga clínica.

e-mail: cassandrapfranca@gmail.com

\section{Júlia de Sens Machado}

Mestre em Psicologia pela Universidade Federal de Minas Gerais - UFMG (Belo Horizonte, MG. Br); Coordenadora do Espaço de Atenção Psicossocial Freud Cidadão; Psicóloga clínica, atualmente dedica-se a pesquisas sobre psicose e poesia na Faculdade de Letras da UFMG. Rua dos Otonis, 909/406 - Santa Efigênia

30150-270 Belo Horizonte, MG, Br

Rev. Latinoam. Psicopat. Fund., São Paulo, v. 15, n. 2, p. 419-434, junho 2012 